\title{
Understanding Scientific Study via Process Modeling
}

Article Type: New Results

\author{
Robert W.P. Luk \\ Department of Computing, The Hong Kong Polytechnic University \\ Hong Kong \\ E-mail: csrluk@comp.polyu.edu.hk \\ Tel: +85227665143 \\ Fax: +85227740842
}

\begin{abstract}
This paper argues that scientific studies distinguish themselves from other studies by a combination of their processes, their (knowledge) elements and the roles of these elements. This is supported by constructing a process model. An illustrative example based on Newtonian mechanics shows how scientific knowledge is structured according to the process model. To distinguish scientific studies from research and scientific research, two additional process models are built for such processes. We apply these process models: (1) to argue that scientific progress should emphasize both the process of change and the content of change; (2) to chart the major stages of scientific study development; and (3) to define "science".
\end{abstract}

Keywords: Process Model; Methodology; Philosophy of Science; Knowledge Management

Biography: Robert Luk received a B.Sc. degree, a Dip. Eng. and a Ph.D. degree from the School of Electronics and Computer Science, University of Southampton, and M.Sc. degree from the Department of Psychology, University of Warwick. He is a visiting research scholar at the Center for Intelligent Information Retrieval, University of Massachusetts, Amherst, USA. He has published over 100 refereed publications (over 40 journal papers), is a PC member of various conferences (e.g., ACM SIGIR) and is a reviewer of various journals (e.g., ACM Trans. Asian Language Information Processing and IEEE Trans. Systems. Man and Cybernetic). He is an associate professor of the Department of Computing, The Hong Kong Polytechnic University. 


\section{Introduction}

"The misnaming of fields of study is so common as to lead to what might be general systems laws. For example, Frank Harary once suggested the law that any field that had the word 'science' in its name was guaranteed thereby not to be a science. He would cite as examples Military Science, Library Science, Political Science, Homemaking Science, Social Science, and Computer Science” (Weinberg, 2001). To avoid misnaming of scientific fields making them explicit may help. In this paper, they are regarded as studies that generate or apply scientific knowledge, but are they the same or different from scientific research? This paper argues that:

Premise 1: Scientific studies, research and scientific research are different processes that contain different interacting (knowledge) elements.

We will argue later that the general types of scientific knowledge, called elements in this paper, are theories, scientific models and experiments. Although these elements may be regarded as components in General Systems Thinking (Weinberg, 2001), they are regarded as entities in our process model which captures the essential knowledge (as data) of the underlying scientific processes (e.g., hypothesis testing). In this sense, our process models may be considered as entity-relationship (ER) diagrams (Silberschatz et al., 2005) for physical realization and knowledge management use. Nevertheless, Premise 1 uses the term 'elements' rather than entities in ER diagrams for generality because such diagrams belongs to one type of conceptual tool in General Systems Thinking.

Premise 1 is supported by construction, i.e., by building process models that define and differentiate scientific studies, research and scientific research. These process models put philosophical issues in their contexts rather than directly resolving these issues. The premise can also help us to distinguish scientific studies and other types of studies. However, for engineering studies that are closely related to scientific studies, it is necessary to differentiate them by their roles, where engineering is about solving 
technical problems and science is about understanding (e.g., (Kosso, 2007)). Thus, we draw the following conclusion from premise 1:

Conclusion 1: Scientific studies distinguish themselves from other types of studies by their processes, their elements and the roles of these elements.

This conclusion suggests that prior philosophical investigations about science, which mainly focuses on either the scientific process or the knowledge elements of science, are not sufficient to distinguish scientific studies from other types of studies. This raises some questions about these prior philosophical investigations on science, i.e.:

(a) Is science solely concerned with scientific research?

(b) Does a scientific study have to have a hypothesis?

(c) Do scientists carry out their investigation using a single scientific method?

(d) Are paradigms (Kuhn, 1962) and the scientific method of the Vienna circle applicable only to science?

Furthermore, these process models, themselves, pose more-basic questions about recent philosophical investigations on science:

(e) Are theories and models approximately true (e.g., Weston, 1987)?

(f) Are all theories incommensurable (Kuhn, 1962)?

(g) Are all computational models complex versions of scientific models?

(h) How does a subject develop into a scientific study?

We argue that philosophy of science should neither just focus on the research processes that are investigated in the conventional philosophy of science (e.g., Kuhn's paradigm and the Scientific Method of the Vienna Circle), nor just focus on the study of scientific knowledge. To support this argument, we realized that simply relying on the research process or the knowledge organization alone cannot differentiate scientific studies from other studies. For examples about research processes, Kuhn's idea about paradigm shift is applicable to the history of the philosophy of science. The scientific method is applicable to criminal investigation. Gauch's (2003) PEL model of scientific reasoning is applicable to law. For other examples about knowledge organization, not only scientific knowledge is organized as theories with principles, law also has its own legal theories and principles. In engineering, there is an 
abundance of performance models. Philosophers have been using logic as a way to organize their knowledge and making inferences. Some argued that science is about understanding, but studies, by definition, seek to understand. Simply using the aim of scientific studies is not sufficient to differentiate between scientific ones and studies in other disciplines.

We argue that scientific studies are distinguished by the combination of their processes, their way of organizing scientific knowledge and the roles that different types of scientific knowledge serve. To support this argument, we develop process models, more specifically data flow diagrams, in order to model scientific studies, research and scientific research as separate processes. Because each process has different knowledge elements, these processes are different. These different elements are different types of knowledge, and each element has its own role in the process model. The role of an element helps to distinguish itself from others, as well as scientific processes and other processes.

The rest of this paper is organized as follows. Section 2 describes our process model of scientific study. Physics is used as an archetype (rather than as a universal science (Białkowski, 1998)) to illustrate the application of this process model. Section 3 develops the process model for research, and combines this model with the one for scientific studies to form the process model for scientific research. Section 4 applies the process models to explain scientific progress, whereas Section 5 applies these models to chart a possible development of scientific study. Section 6 is about related work. Finally, Section 7 draws our conclusion about what is science.

\section{Process model}

We argue that:

Definition 1: A scientific study has three (knowledge) elements: theory, model and experiment. 


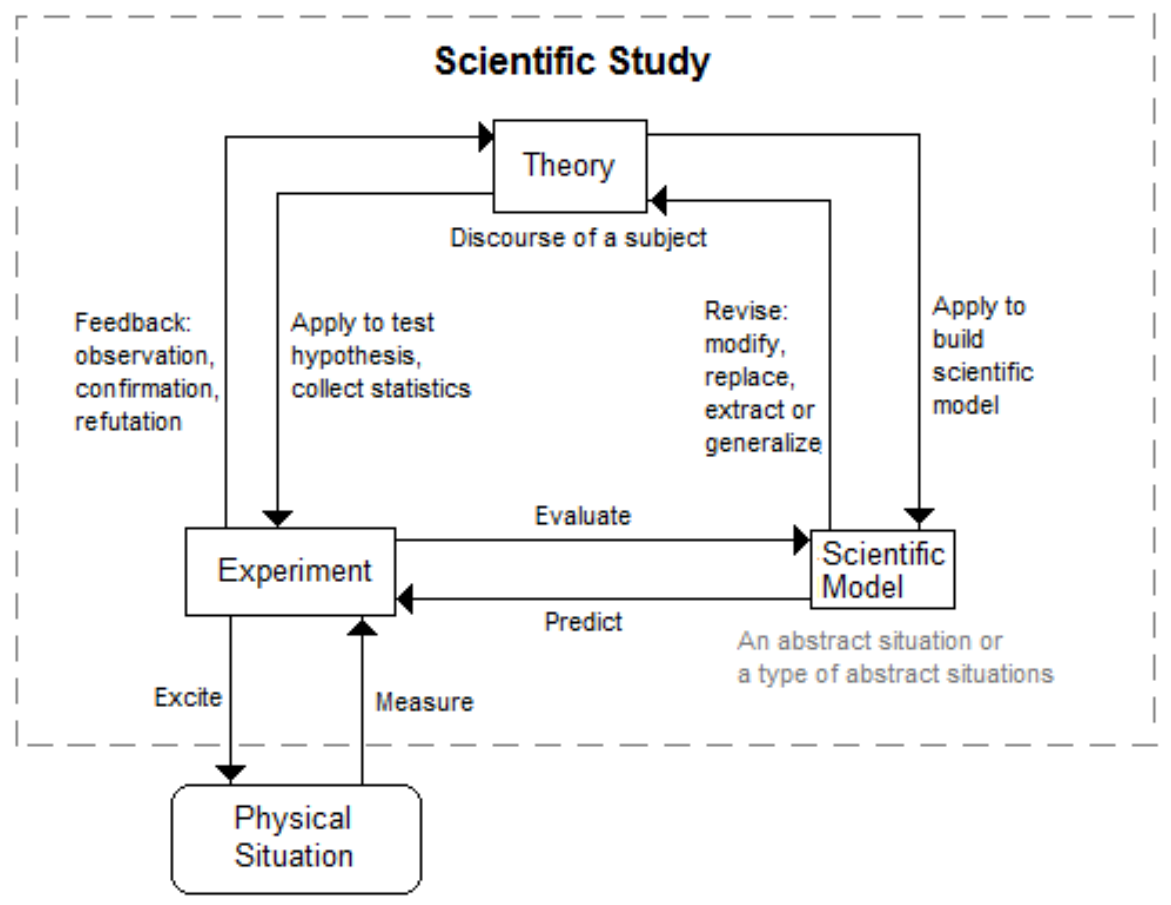

Figure 1: A process model of scientific study.

This is supported by providing evidence that these three (knowledge) elements are important to science. For example, large sums of funding are used to build particle accelerators in order to conduct experiments for particle physics research. Also, the scientific model of nuclear fission behind nuclear power station is important to predict the amount of energy released from certain amount of enriched uranium. The scientific model of nuclear fission uses the famous equation, $E=m c^{2}$, to calculate the amount of energy released during fission. This equation is derived from the theory of special relativity. Experiments (Franklin, 1981), scientific models (e.g., Swanson, 1967) and theories (e.g., Alexander, 1958) have also been extensively discussed in philosophy of science. Therefore, they are important in both science and the philosophy of science, but they are not integrated as elements in a process model as described in this paper.

Our process model of scientific study is shown in Figure 1. It has entities (as rectangles) and processes (as directed lines). It has four entities: the theory entity, the model entity, the experiment entity and the physical situation entity. An entity is an extension of a set of instances, and one instance of an entity is called an entity instance (Silberschatz et al., 2005). For example, the theory entity can denote a single theory or a set of theories. The connections between theories (in the form of a 
hierarchy, for example) are hidden in the process model at this stage. Similar to entities, a process can denote a single process instance or a set of process instances. The physical situation entity is an external entity that is being studied and is not a part of the scientific study. This is the only entity that is not a knowledge element in Figure 1. Table 1 shows some details about theories, models and experiments.

Table 1: A summary of various aspects of elements of science

\begin{tabular}{|c|c|c|c|}
\hline Aspect & Theory & (Scientific) Model & Experiment \\
\hline \multirow[t]{2}{*}{ Aim } & $\begin{array}{l}\text { Generalize the scientific } \\
\text { models into a set of } \\
\text { general/universal } \\
\text { statements }\end{array}$ & $\begin{array}{l}\text { Describe physical situations } \\
\text { as accurately as possible }\end{array}$ & $\begin{array}{l}\text { Collect information from } \\
\text { physical situations }\end{array}$ \\
\hline & $\begin{array}{l}\text { Find essential aspects of } \\
\text { the subject }\end{array}$ & & \\
\hline \multirow[t]{3}{*}{ Usage } & $\begin{array}{l}\text { Construct models for } \\
\text { novel situations }\end{array}$ & $\begin{array}{l}\text { Make predictions of future } \\
\text { events }\end{array}$ & Evaluate models \\
\hline & $\begin{array}{l}\text { Explain observed } \\
\text { phenomena }\end{array}$ & Test theories & Test theories \\
\hline & & & $\begin{array}{l}\text { Explore characteristics of } \\
\text { the subject }\end{array}$ \\
\hline Scope & $\begin{array}{l}\text { Define the scope of the } \\
\text { investigation }\end{array}$ & $\begin{array}{l}\text { Define a set of applicable } \\
\text { physical situations that the } \\
\text { model can describe }\end{array}$ & $\begin{array}{l}\text { Define a type of physical } \\
\text { situations for collecting } \\
\text { information }\end{array}$ \\
\hline $\begin{array}{l}\text { Qualitative or } \\
\text { Quantitative }\end{array}$ & $\begin{array}{l}\text { Qualitative with named } \\
\text { quantities } \\
\text { quantiative }\end{array}$ & Qualitative and quantitative & Usually quantitative \\
\hline $\begin{array}{l}\text { Measure of } \\
\text { Quality }\end{array}$ & Truth value & Accuracy (or Error) & $\begin{array}{l}\text { Repeatability/Reliability } \\
\text { (Statistical Significance) }\end{array}$ \\
\hline $\begin{array}{l}\text { Construction } \\
\text { Method }\end{array}$ & $\begin{array}{l}\text { Use conceptual tools, } \\
\text { like logic, to make } \\
\text { general or universal } \\
\text { statements }\end{array}$ & $\begin{array}{l}\text { Use mathematics or logic as } \\
\text { tools to construct models }\end{array}$ & $\begin{array}{l}\text { Use experimental design } \\
\text { techniques or statistical } \\
\text { methods }\end{array}$ \\
\hline
\end{tabular}

Details about the entities at this stage are deliberately hidden. The purpose is to simplify the study so that we can identify what are the major elements of science and how they interact. Scientists are not included in the model in Figure 1, because of limited space, even though we recognize that scientists themselves are important elements in the process of science. At this general level, it is customary not to model the operators (i.e., scientists) in the process models. According to Figure 1, theories and models can only get in touch with physical situations via experiments. Since an entity and a process are sets, a theory entity instance that generalizes a set of scientific model entity instances is represented only as a single process from theory to scientific model in Figure 1. The concern of this process model at this general level is about the 
existence of the process (including its direction) between entities, leaving out its details (e.g., one-to-one mapping, one-to-many mapping or many-to-many mapping). Table 1 shows different aspects of different elements of scientific studies. The aims of each element are specified in Table 1. These aims define the different roles that these elements play. They help scientific studies to differentiate themselves from other types of studies. The measures of quality of each element are different because the aims of each element are different. The scope of an element specifies the regime in which the element is applicable. The remaining aspects provide further differences between different elements of scientific studies.

\subsection{Instance Diagram}

For more details in Figure 1, we can draw an instance diagram (Silberschatz et al., 2005) that is a realization of the process model in Figure 1. For example, Galileo carried out two well-known experiments that are called the Tower of Pisa experiment, and the bell and ball experiment. These two experiments refute Aristotle's theory that the heavier object falls faster than a lighter object. Figure 2 shows a realization of the process model of Figure 1 in this case. Figure 2 does not have any scientific models because the experiments did not need complex calculations. These experiments only need to measure the duration for the heavier and lighter objects to reach the floor, in order to refute Aristotle's theory.

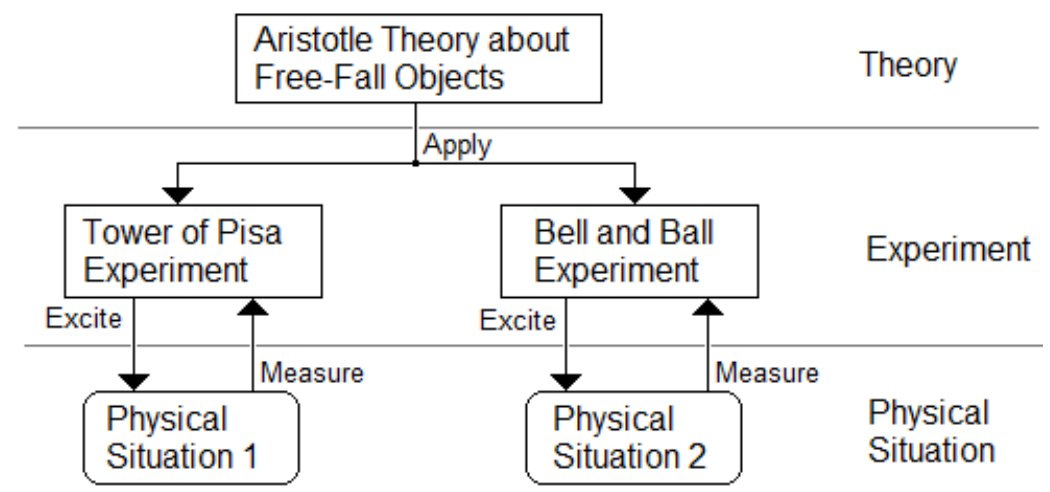

Figure 2: An instance diagram of Galileo's experiments.

For a more elaborate example than Galileo's experiments, we chose Newtonian mechanics, because it is well known and it is an archetype of a mature scientific study that lasted for over two centuries until it was shown to be a special case of the theory 
of general relativity. In Newtonian mechanics, many experiments involve complex quantitative relationships that are derived or constructed from the principles (or laws) of the theory. For example, in Figure 3(a), a trolley is sliding down a slope with a constant degree $\theta$ of inclination. Unlike the bell and ball experiment conducted by Galileo, we are not simply interested in whether trolleys of different weights traveling from the top to the bottom of the slope arrive at the same time. Instead, we are interested in the quantitative relationship between $\theta$ and the time that the trolley travels from the top to the bottom of the slope. If there is no friction, then

$$
d=\frac{1}{2}(g \times \sin \theta) \times t^{2}
$$

where $d$ is the distance that the trolley travels in time $t$, and $g$ is the acceleration due to earth's gravity. This equation is obtained by constructing a model as shown in Figure 3(a) using not only Newton's three laws of motion but also Newton's universal law of gravitation. The same laws can be applied to the projectile experiment shown in Figure 3(b). In this case, a canon fires a ball with $\theta$ degree of inclination. If the canon ball is fired at the initial speed $v$, the quantitative relationship in this model will be

$$
d_{h}=\frac{2 v^{2} \cos \theta \sin \theta}{g},
$$

where $d_{h}$ is the horizontal distance that the canon ball travelled.

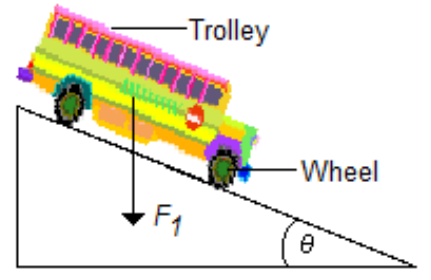

(a)

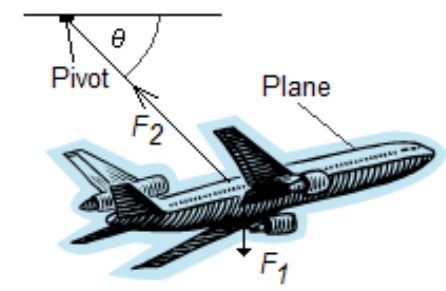

(c)

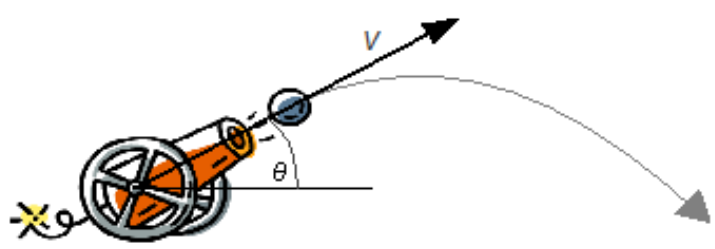

(b)

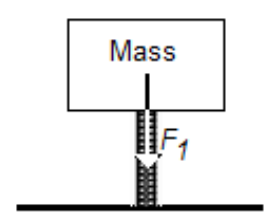

(d)

Figure 3: Four models of physical situations where $F_{1}$ is the gravitation force due to the mass of the object. We call these models with the following names: (a) rolling model, (b) projectile model, (c) centripetal model and (d) vibration model. 
Figure 3(c) shows a model of a toy plane revolving around a pivot with constant speed $v$ at $\theta$ degree of declination. The tension on the string connecting the plane and the pivot is $F_{2}$ that both lifts the plane and provides the centripetal force for the plane. If the string is $d$ meters long, then using Newton's laws and the mathematics of rotating reference frame, the quantitative relationship will be:

$$
v=\sqrt{g \times \cot \theta \times \cos \theta \times d} .
$$

This example shows that the law is applied in combination with other mathematical techniques in order to produce some quantitative relationship that can be verified or applied in practice.

Figure 3(d) shows a model of the vibration experiment that involves a mass and a spring. When the mass is displaced by a certain vertical distance from its equilibrium position then the mass under free vibration oscillates at a frequency $f$. Apart from the laws in Newtonian mechanics, we need an empirical relationship, called Hooke's law, to specify the amount of force, $S$, that is exerted by a deformed spring with a distance. According to Hooke's law which only applies to certain material in certain configuration, $S=-k d_{v}$, where $k$ is called the spring constant, and $d_{v}$ is the amount of deformation of the spring. Using Newtonian mechanics with Hooke's law, a quantitative relationship is found for a freely vibrating rigid object attached of mass $m$ to a spring

$$
f=\frac{1}{2 \pi} \sqrt{\frac{k}{m}}
$$

This special case illustrates that Newtonian mechanics does not contain all laws involved in the construction of a model. Instead, it contains laws that are commonly found or those that are applied to a wide variety of situations. On the other hand, Hooke's law is applicable to a certain type of spring. More complex vibration systems can be analyzed using Hooke's law together with Newtonian mechanics. Together, these laws form a focused theory that explains and quantifies vibration systems of rigid bodies suspended by linear-elastic material.

Figure 4 is an instance diagram showing the application of Newtonian mechanics to construct the four models in Figure 3. It also shows how Newtonian mechanics are 
subsumed by the theory of general relativity. Laws in Newtonian mechanics are applied in all four models. Some suggested that these are universal laws that are applicable to all situations. Later, the confirmation of the theory of special relativity restricted Newtonian mechanics to the regime where the speed of objects is much less than the speed of light. Scientists seek to establish laws or principles that are applicable to many different situations within the regime of study. Contrasting with Hooke's law, its application is much more restricted than those for Newtonian mechanics. As a result, there is a distinction between focused theories that explain certain phenomena (like simple harmonic motion) and the general theories that are applied to build models for a wide variety of situations.

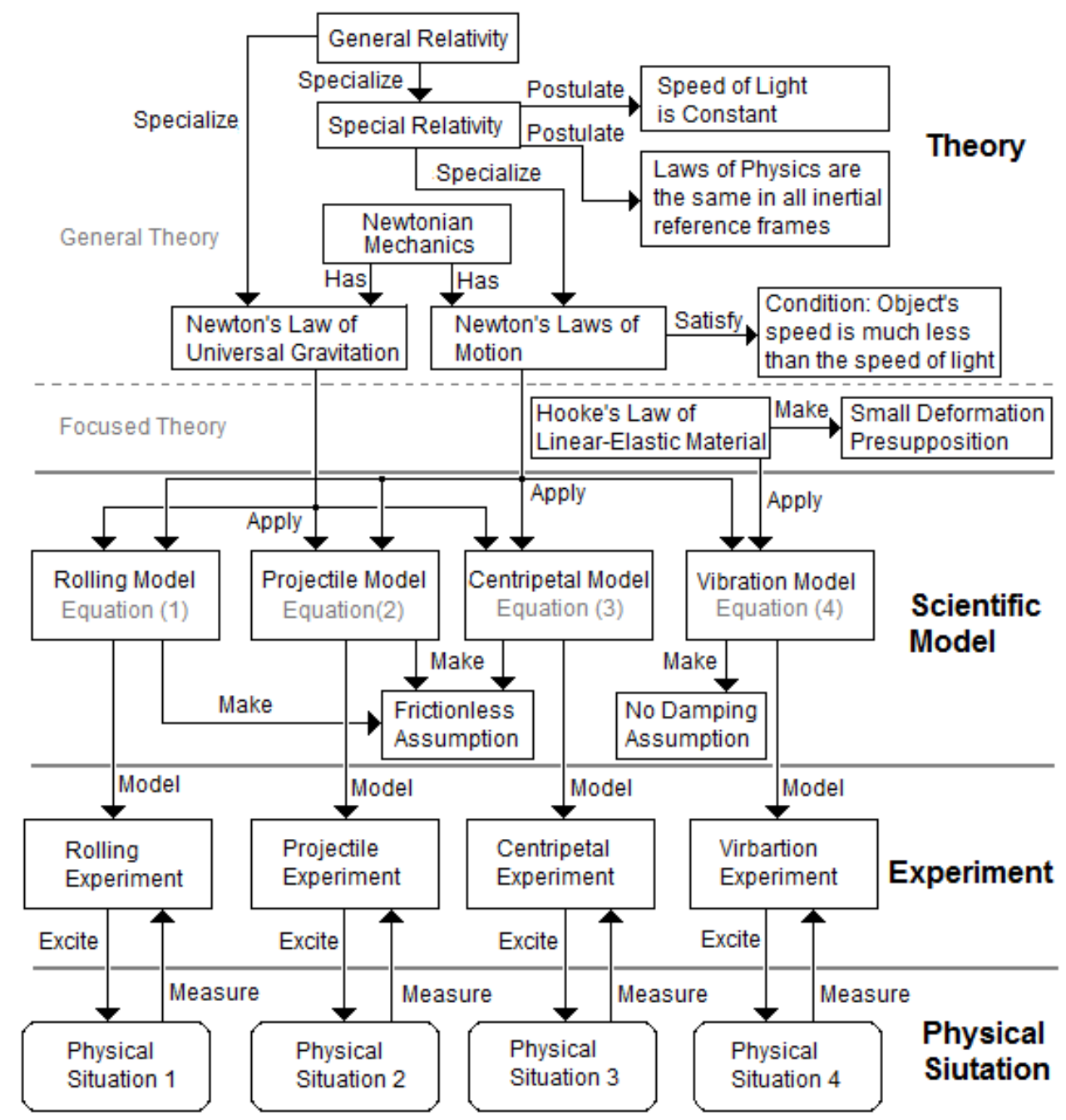

Figure 4: An instance diagram describing the application of Newtonian mechanics (under the theory of general relativity) to the four situations in Figure 3. 
Figure 4 also shows that some theories do not have any model as part of the theory. Instead, models are built when the situation arises. Earlier, each model in Figure 3 has a quantitative relationship (i.e., equations 1-4) that is derived from the theory so that this relationship can be quantified and verified in practice. However, not all models are quantitative. For instance, Galileo's experiments about free-fall objects refute Aristotle's theory by observing whether objects of different weights reach the floor at the same time when these objects fall under the same conditions.

In Figure 4, the experiment entity instances and the (scientific) model entity instances can be distinguished by information related only to those entity instances alone, where such information is not shown in the diagram for clarity of presentation. For example, some field experiments may have been carried out under specific conditions which are recorded as part of these experiments and not part of the scientific models. Controlled experiments may specify what instruments are used for making measurements which are not documented with the scientific models. The detailed derivations of the quantitative relationships are documented with the (scientific) model instances rather than the experiment entity instances. In addition, a (scientific) model entity instance may be used by different experiment entity instances to measure different quantities (e.g. angle $\theta$ or distance travelled) in its quantitative relationship.

\subsection{Scientific Study Elements}

In this section, we relate philosophical issues with our description of the elements in scientific studies. Our description of these elements does not resolve these issues, but put them into the context of scientific study rather than scientific research.

What is a theory? There are at least two different types of scientific theories: general and focused theories. A general theory aims to generalize (e.g., Nugavey, 1985; Bailer-Jones, 2003) both models and more focused theories in order to provide a parsimonious description of them. For example, the general theory of electromagnetism as summarized by Maxwell's equations combines the laws of Faraday, Ampère and others. So, a theory consists of some general/universal statements (Nowak, 1972; Moor, 1978; Bailer-Jones, 2003; Liu, 2004) of the subject 
of interest (or within some regime). These statements can be ascribed with truth values so that they can be tested empirically (as opposed to those that are not falsifiable, e.g., (Magnani, 1999)). It also has its own concepts (e.g., momentum) that are measurable or related to physical situation. A theory must have a statement about the scientific discourse to define its scope. It may have some presupposition (Gauch, 2003) that the theory assumes. Also, it may have principles (Suppes, 1995) that models or experiments are intended to obey. In the general case, these general statements can be grouped into different types, such as principles, presuppositions, conditions, and assumptions.

Statements in a theory are intended to be true (Psillos, 2000). Some statements are not always true but they are stated in the theory in order to simplify the situation for modeling or explaining a physical situation, thereby leaving out the details that are not the focus of the inquiry (Nowak, 1972; Liu, 1998; Bailer-Jones, 2003). In addition, this treatment of statements is useful to deduce new results for prediction, verification, validation, falsification and model construction (Portides, 2005). This is also useful to differentiate the qualifying measure of scientific knowledge as being true or false that is applied to statements of a theory, as opposed to being accurate or not, which is applied to scientific models. Statements that are intended to be true may be regarded as belief (Psillos, 2000), but scientists may not necessarily believe in the statements of a theory when they are testing the theory. We can summarize the notion of truth in scientific knowledge as follows:

Definition 2: When a statement in a scientific theory is said to be true, this means that the theory asserts that the objects or relations specified in the statement are manifested and are operating within the regime of study.

A theory may have general qualitative models, because they can account for a finite number of types of situations to describe. Alternatively, a theory may not have any qualitative models, because there are an unknown number of possible situations to describe. In general, it is also possible that a theory contains a number of theories with more limited scope than the original theory. 
There are different kinds of theories. A mathematical theory is quantitative, and it focuses on solving some mathematical problems. Some mathematical theories may have been successfully applied across various disciplines (e.g., von Bertalanffy, 1950), and many mathematical theories have been axiomized. While theory axiomization (Liu, 1998) can distinguish the elementary concepts from the derived concepts, it should be pointed out that a mathematical theory can be axiomized differently (i.e., there can be more than one set of axioms for a theory). A logical theory is a qualitative theory based on logic. The focus of such a theory is on valid reasoning or inferences based on its premises; PEL (Gauch, 2003) is a good example.

A scientific theory is a theory that has both qualitative and quantitative aspects, as well as empirical significance. So, it is not unusual to find named quantities in statements of a scientific theory. In some scientific theories, they have a set of general equations (e.g., Maxwell's equations) that can be used to develop scientific models. While scientific theories are quantified mathematically, many scientific theories are not axiomized, because of the fact that the axioms are more about the mathematical properties rather than the scientific properties (i.e., the principles or laws) of the subject of study. An established scientific theory must be self-consistent, so this would demand good reasoning (Gauch, 2003). Otherwise, the theory needs to be revised and replaced. The theory needs to be quantified because it involves some measurements for validations and predictions. An established scientific theory must relate to some physical events or their derivatives, so that it has empirical significance. Some theories are based on more fundamental, and therefore more general theories. For example, the theory of sound propagation in a solid can be built on Newtonian mechanics. Usually the fundamental or general theories have a wider scope of application than the more focused theories that explain certain physical phenomena.

What is a scientific model? A model is a description of a type of physical situations, so it is an abstract or conceptual situation (Portides, 2005) that is constructed (Hennig, 2010) as an approximate version of the corresponding physical situation being studied. On the one hand, a model aims to describe or predict the physical situation as accurately as possible. So, a scientific model is usually quantitative, and it borrows mathematics (Suppes, 1960) for the purpose of quantification (Davy, 2003). On the other hand, a model simplifies a physical situation by ignoring details that are thought 
to be insignificant or unrelated to the inquiry. So, a model typically has some simplifying assumptions that are made (Achinstein, 1965), not because they are true (Nowak, 1972; Morton, 1993) but because they are convenient for modeling and for the scientific study. This kind of simplification provides a handle to the underlying knowledge of the subject. Rarely, scientific models are more complex than necessary. Such instances can occur when scientists borrow sophisticated mathematical models handling as many factors as possible so that their models or some techniques can discover the critical factors for predictions. Therefore, a scientific model sometimes can be a simplification of or an over-complication (in certain respect) of the physical situation. However, such a model is always intended to be a good approximation of the physical situation.

It is not necessary that the description of an abstract situation has to be isomorphic or similar (Suárez, 2003) to the corresponding physical situation. For example, the descriptions may be simply describing just the input and output of a physical situation, as well as their relationships, or the descriptions may be an elaborate one that entails the detail and possibly hidden mechanics of the situation.

In mathematical terms, representation (more specifically, representation theorem) is an isomorphism or a bijective map. A bijection has two properties: injection (i.e., oneto-one mapping) and surjection (i.e., onto mapping). Because a model leaves out details of the physical situation, some objects or details in the physical situation are not in the model. In this case, the mapping from the objects of the model to objects in the physical situation will not be surjective, and therefore not bijective. Even if we limit the physical objects that matter to the study, we cannot be sure whether the mapping is surjective, because we do not know whether there are any hidden variables or latent variables (Bartholomew and Knott, 1999) even though there are statistical techniques (e.g., principal element analysis) to handle such variables.

Injective map is desirable because we can refer to objects in the physical situation unambiguously. However, we are also not certain whether the mapping between objects in the model and those in the physical situation is injective. This is because the intended objects that are recognized as one type of objects in the physical situation may turn out to be two different types of objects. Therefore, models are only intended 
to map to objects on a one-to-one basis (i.e., injective) or in a stronger sense represent the physical situation (i.e., a bijection). While science may appear to rest on shaky foundations, we need to recall that a model does not survive on the basis that they have a one-to-one mapping to the physical situation. Instead, it survives because it is able to predict the outcomes accurately and reliably, able to predict more types of physical situations and be consistent with (existing) theories. In order to increase both accuracy and reliability of predictions, some scientists even investigate how these are done using more variety of data (e.g., Kruse, 1997). Given that the mapping between objects of the model and objects in the physical situation is usually intended to be injective (or more strongly bijective), we prefer to say that models are approximate versions of the corresponding physical situations. We summarize the previous discussion about the role of scientific models, which is related to the philosophical debate on realism:

Definition 3: A scientific model is said to be realistic when it can predict quantities accurately and reliably in uncontrolled experiments within the regime of study.

The level of accuracy and reliability makes reference to the current achieved level. As the lowest baseline of comparison, this level of accuracy and reliability should be better than the level predicted by a naive random model that forms the null hypothesis for statistical tests of reliability. Such a random model has little domain-specific knowledge, so it cannot claim to exhibit any understanding of the subject of study.

The development of scientific models involves ignoring details of the physical situation or making assumptions for simplification. The justification of ignoring certain details or including what are considered important factors may be based on intuition, common sense (Miscevic, 2001), philosophical issues (Bailer-Jones, 2003) past research issues or some creative process (Beveridge, 1957; Bailer-Jones, 1999). For instance, formative research where little is known for certain about the particular field of investigation may rely more on common sense to identify governing factors of a model. Experiments can be designed to test which of these factors are important in the subject of study. For some established area of science, existing theories, models, experiments and research issues can guide the selection or addition of details in the 
model. Thought experiments may be particularly suitable in this kind of knowledgerich domain (Damper, 2006). In the case of the application of an existing theory to develop new models for novel physical situations, the physical situation may provide guidance to include additional details for accurate modeling (Bailer-Jones, 2003).

What is an experiment? An experiment is carried out in a physical situation. The aim of doing an experiment is to collect information from the physical situation for various purposes. The information can be used to support or deny a theory or its elements. It may be used to evaluate a model. It may be used to find characteristics of the phenomena for building models or theories. In order to obtain information from physical situations, the experiment must do some measurement. An experiment may directly excite the physical situation because it can control the excitation, or it may make measurements using a natural excitation source (e.g., observation of stars). The quality of an experiment depends on many factors (Franklin, 1981), and probability and statistics are increasingly used to assess the reliability and repeatability of the experimental outcomes (Suppes, 2007).

There are different types of experiments. Controlled experiments are usually used to validate theoretical statements. The experiments are controlled so that the impact of the intervening or interfering factors is reduced as much as possible. In some cases, the controlled experiment becomes so simple (or so focused) that it is not necessary to declare a scientific model is used to quantify the controlled experiment and predict its outcomes. Instead, scientists directly show how the interested quantities are calculated in order to show the manifestation of some theoretical statements (e.g., Rainville et al., 2005), and the unnamed scientific model is literally hidden from communication. Natural experiments belong to another type of experiments. The focus of such experiments is to collect data in a practical situation rather than in controlled environment. Such experiments may determine the inadequacy of scientific models or theories in practical situations.

What is a physical situation? It is a state of affairs in which an experiment is carried out. It is physical because the scientists designed the experiment to observe the "real world" in a particular intended context. In other words, a physical situation is some part of the real world that is the subject of study. 
What is the real world? The real world refers to the totality of physical situations that we, as a whole, experience in the past, in the present, as well as in the future. Different people have different real worlds in mind because we are exposed to a limited scope of the real world. Many scientists only deal with the limited physical situations related to their subject of study (or a regime). Some scientists believe that the real world is the same all the time and everywhere, because they believe that this makes the real world objectively accessible and universally applicable. Some scientists do not want to make a leap of faith to generalize their own daily and scientific experience to the real world as a whole. However, all scientists would agree that they intended their experiments to be conducted in objectively accessible physical situations (and not necessarily the real world as a whole) so that their scientific work can be communicated to others for verification and agreement (Hennig, 2010). This objective accessibility includes subjective descriptions of mental phenomena (Nagel, 1974) since these descriptions may fall into certain categories or types when they are collected from many (human) subjects and since descriptions are objectively accessible.

\subsection{Process}

Having described the different entities, our discussion focuses on the processes. One of the processes is the construction of scientific models based on theories (Bod, 2006; Morrison, 2006). A scientific model should be consistent with the theory. The applications of the theory to build the model should be based on valid reasoning to ensure or demonstrate consistency between the application of the theory and the scientific model. Since a theory is a discourse, selective statements, like principles and assumptions, which can be ascribed with truth values, can be used for scientific model construction. It is also not necessary that the entire theory be applied to build a scientific model. For instance, the vibration model in Section 2.1 does not use all three Newton's laws of motion.

In the other direction, the revision process may modify a theory when its model is being modified for better predictions. The revision process also generalizes successful scientific models into a theory so that the essential aspects of these models are 
identified in the theory. These essential aspects may be the principles or assumptions of the theory, which are independent of the models and are applicable to different abstract and physical situations. For example, the principle of conservation of energy is applicable to quantum mechanics as well as to Newtonian mechanics.

The processes between the scientific model and the experiment are the prediction and evaluation of models. A model makes predictions of physical situations that it intends to be applied to. A prediction is commonly understood to be a quantity but the prediction can also be a dichotomous value. Evaluation involves collecting data where the experiments are repeated a number of times for reliability assessment. The collected data are processed to inform scientists on how accurate the model makes prediction. Statistical tests can be carried out to give scientists some measure of reliability of the outcomes, e.g., confidence levels. In view of the results in experiments, a model may undergo revisions and possibly the theory also needs to be revised.

The processes between theory and experiment are concerned with collecting data from experiments to feedback information to the scientists for the support, denial, revision or construction of the theory. What kind of data to collect depends on the need of the scientist. For instance, when there is no established theory in the current study, a scientist may collect statistical summary data in order to begin building a theory. On another occasion, a scientist may want to test a certain part of an established theory; a hypothesis about the theory can be formulated and tested by experiments. This is the common notion of scientific method of the Vienna Circle, which is originated from the inferences as observed by Pierce (1989) in science. This inference includes abduction, deduction and induction. Abduction is to guess plausible causes or explanations of the observed effect. To test which causes or explanations, alternative outcomes serving as hypotheses are deduced from such causes or explanations. Experiments are carried out to inductively infer which cause is responsible for the observed effect. Such inference is being adopted in the emerging cyberinfrastructure for geosciences (e.g., (Brodaric and Gahegan, 2006)).

Some historical scientists have been critical of the scientific method using induction as the only acceptable method of scientific inquiry (e.g., (Cleland, 2001)) because 
their experiments may not be able to be repeated in laboratory or may not be able to be found in the field. Examples of historical scientific inquiries include the meteoriteimpact hypothesis for the extinction of the dinosaurs and big-bang theory of the origin of the universe. Instead of repeating the experiments, scientists find pieces of evidence from different sources or of different character, which are documented in the experiment entity instances (called cases), to support the hypothesis or theory, and to eliminate the alternative hypothesis or theories. Sometimes, scientific models are needed to determine certain quantities that can be observed now (e.g., the background radiation due to the primordial explosion according to the big-bang theory). Such quantity provides a piece of evidence to support a particular hypothesis or theory. For historical science the method of inquiry is very similar to criminal investigation, and their differences are the aim of the investigation and their knowledge elements.

\section{Computational Models}

As computational models are becoming increasingly significant (e.g., weather forecasting), we are motivated to include some computational models (Moor, 1978) as scientific models. The digital computer, which is a computing device based on logic and mathematics, is essentially executing a detailed version of some scientific models. The problem with perceiving a computational model as a scientific model is the complexity of a computational model. Many scientific models can be comprehended by human but the complexity of a computational model may be very difficult to understand. In addition, a computational model incorporates many details that are considered not essential in a scientific model. This raises concern whether the prediction problems are due to deficiencies in the basic scientific models, or due to inappropriate, or irrelevant, or the lack of details in the computational model. We believe that computational models which defy human understanding cannot qualify as a scientific model.

We refer to computational models that are shown to correspond to scientific models after simplifications as computational scientific models. Such models are regarded by us as a type of scientific models. The other scientific models are called conventional scientific models. Figure 5 shows a detailed diagram where the scientific model in Figure 1 is divided into conventional and computational scientific models. 
The purpose of developing computational scientific models is to produce simulated experimental results (Boon, 2003) in order for the scientists to understand what are the outcomes and their likelihood, as well as for appreciating the significance and impact of these outcomes. The need of such appreciation and understanding is because of the difficulties to carry out the experiment. Such difficulties may stem from the scale of the experiment, the controllability of the experiment or the fatality of the experimental outcomes.

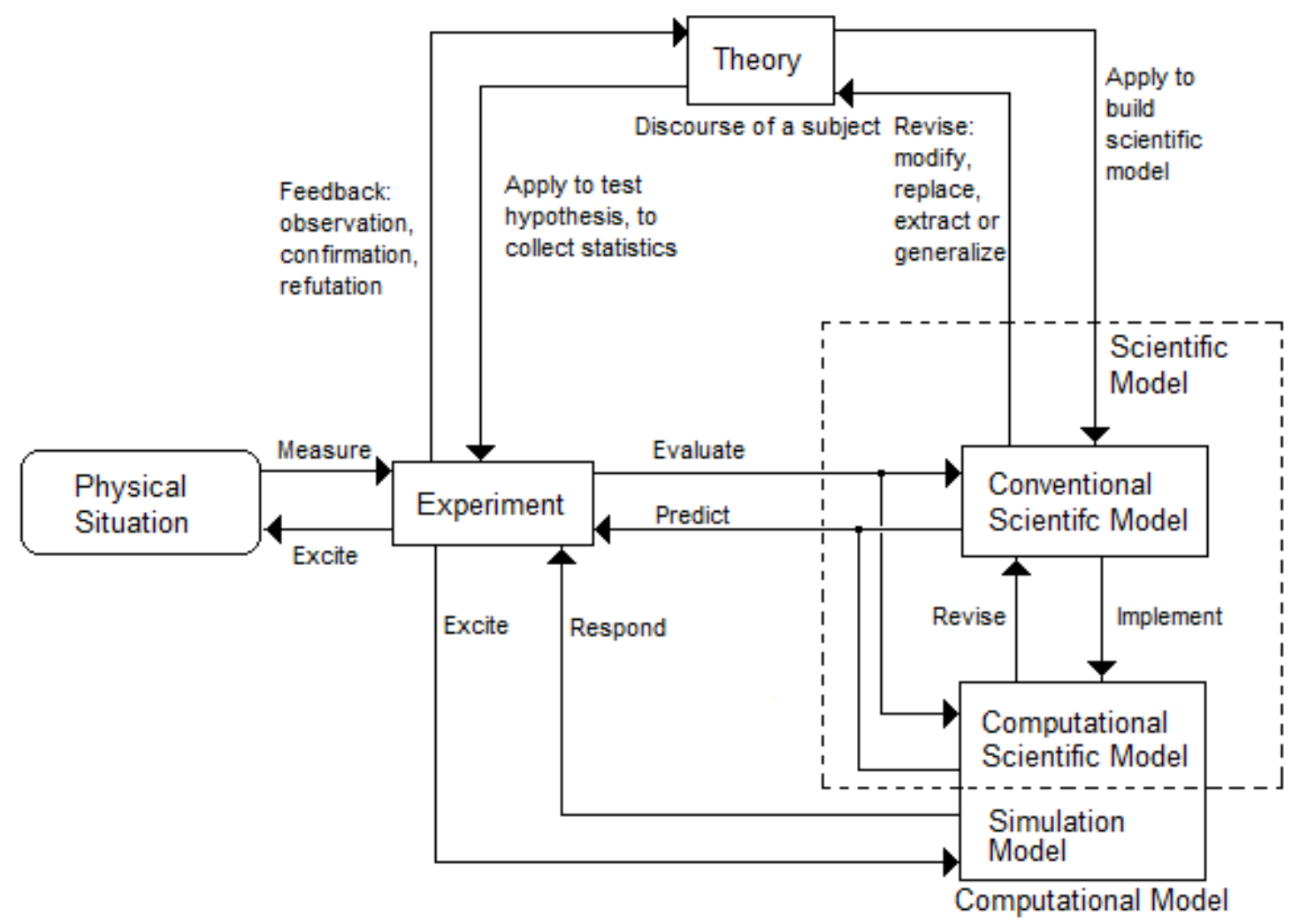

Figure 5: A process model of scientific study that includes computational models.

Some computational models cannot be called computational scientific ones because they drastically simplify the physical situation for controlled studies so that they can be used for testing theories or hypotheses. These computational models are called simulation models which may be used in the experiment. For example, the ELIZA program (Weizenbaum, 1966) held conversations with human subjects in the experiment, and some subjects considered that the program responses were by human subjects. In this case, the ELIZA program was denied by Weizenbaum as a theory of conversation because the program only relies on superficial syntactic and semantic 
cues to respond. In addition, human subjects have access only to the ELIZA program textual output. In such a controlled environment, this experiment using a simulation model may be considered as testing the hypothesis that syntactic and semantic cues are sufficient for holding conversations rather than testing the ELIZA program as a computational scientific model of human conversation.

Simulation models belong to the experiment entity as such models are experimental tools for investigation (Humphreys, 1995; Hartmann, 1996). However, the simulation model entity is placed side-by-side with the computational scientific model entity in Figure 5 in order to show that they are both computational models, and that simulation models may become computational scientific ones when they are fully developed for realistic simulation in more uncontrolled environments. Furthermore, simulation models may be evaluated on how realistic they are, and computational scientific models may be used to generate responds in the experiment.

Figure 5 illustrates the flexibility of the process model because each entity or relationship can potentially be developed into more detailed process models themselves. Effectively, the complexity of the process can be hidden or emerged depending on the required level of details of the process. In the rest of this paper, we will discuss the scientific model for generality, rather than its three detailed entities, conventional scientific models, computational scientific ones and simulation models.

\section{Scientific research}

Some consider that scientific studies and research are synonymous, and empirical results in research papers are demanded. However, some significant research papers do not have any direct empirical support. For example, the paper by Einstein (1905) on the theory of special relativity does not have any first-hand empirical results to support the theory. Important research papers that survey particular fields of inquiry also do not have any first-hand empirical results. In this section, we use our understanding of scientific study to relate and differentiate between scientific studies and other related areas. 
We believe that research, instead of scientific studies, is a problem-solving activity (or more generally a question-answering activity), even though there are many ways in which interest in research begins (Struan, 2001; Koshland, 2007). Research aims to discover new ideas for solving problems. It can be framed as a scientific study (Lauden, 1987) because it can involve building new theories or scientific models, conducting new experiments, making new extension of a theory or a model, making new observations of existing experiments, etc. However, some research cannot be considered as scientific study. For example, there is research done in literature in order to discover a new perspective or understanding of some classical literature. At the other end of the spectrum, not all scientific processes are research. For example, scientific processes may be used for forensic studies in criminal investigation, or for monitoring the amount of toxic chemicals in food for public health and safety. Instruments used for scientific studies are also used in these scientific processes but they do not serve to find better models or theories as in research. Similar to scientific research, trained scientists and laboratory technicians are employed to carry out these experiments or tests in government laboratories. However, these confirmation studies are carried out for monitoring purposes and they are not carried out as scientific research for the better understanding and modeling of toxic chemicals. While research and scientific studies have a significant overlap, they are not synonymous.

To substantiate that research and scientific studies are not synonymous, we developed a process model of research (Figure 6). Our process model of research is similar to our process model of scientific study (Figure 1). The experiment and physical situation entities of research are the same as the experiment and physical situation entities in Figure 1. The solution entity in Figure 6 corresponds to the model entity in Figure 1. This is because sometimes the solutions involve mathematical models for solving a research problem. Also, a solution solves a particular problem in a particular situation, which is similar to a model that describes a specific situation. The problem entity in Figure 6 corresponds to the theory entity in Figure 1. This is because a problem can be considered as a kind of generalization of the different solutions for the same problem, similar to a theory being a generalization of a number of scientific models. 
Unlike scientific theories, a research problem does not necessarily need to have any empirical significance. For example, some research in mathematics aims to discover a solution for a well known mathematical problem (i.e., a conjecture). A mathematical proof is needed. This means that some research does not necessarily have empirical significance. For instance, survey-type research papers synthesize past research works into a coherent account of current frontiers of knowledge and current issues of the particular chosen research topic. Such reviews (e.g., papers in ACM computing survey) seldom report any first-hand experiments about the physical world.

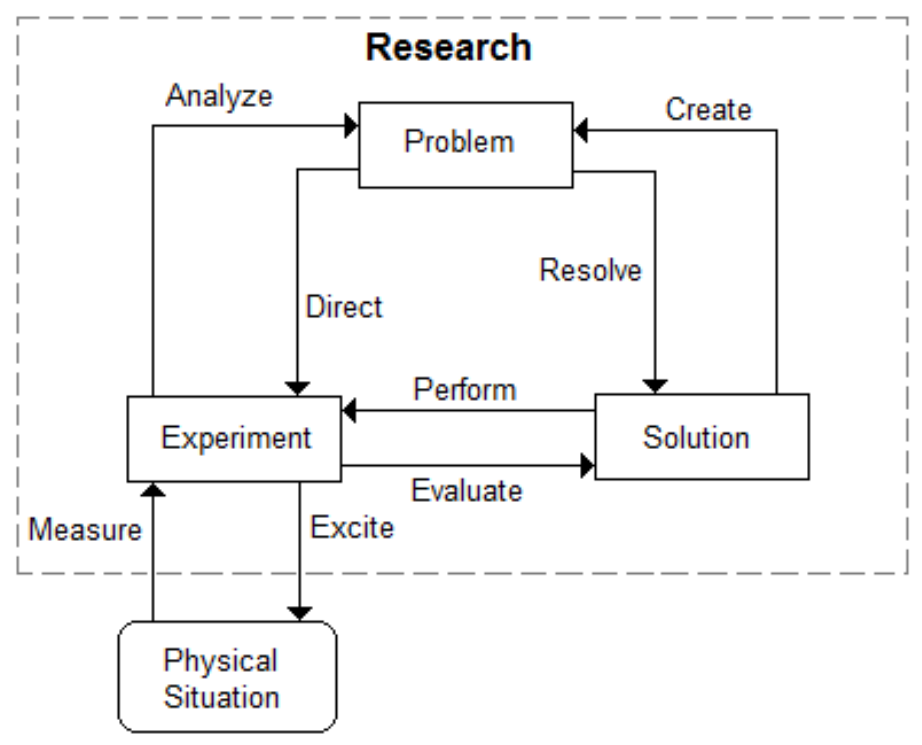

Figure 6: A process model of research.

Similar to scientific theories, a research problem also has a number of general statements that describe the nature of the problem being solved. Therefore, statements that define the scope of the problem are similar to the statements that define the scope of a scientific theory. However, many types of statements of a research problem are not related to statements in a scientific theory. For example, the constraints and objective functions of a research problem are not necessary parts of a scientific theory.

The focus of many engineering research works is to find better solutions to a technical problem (Boon, 2006). These solutions may involve some mathematical techniques or experimental know-how. However, sometimes, these solutions are models of physical situations. The parameters of these models are then optimized in order to solve the problem both effectively and efficiently. As a result, these models are called 
normative models that prescribe the best action to take in the given situation. These models are different from the descriptive models of science, which aims to describe the situation accurately. Some solutions solve very specific problems, and others can solve a variety of problems. Therefore, different names of solutions are created depending on how general a problem that they can solve. The most specific solution is called a technique, followed by algorithms, methods, approaches, and methodologies.

Similar to the common notion of scientific study (i.e., the "scientific method" advocated by the Vienna Circle), research always starts with a research problem (more generally, the research question) (Sintonen, 2004) that is not trivial to solve (more generally, the answer). The research problem or question is similar to the hypothesis in the scientific method (Sintonen, 2004). Unlike the scientific method that demands a hypothesis to be related to some theory or some statement in a theory that explains observed phenomena, the research problem or question does not need to be related to any theory, nor related to any observed phenomena. For examples, scientists (Rainville et al., 2005) can develop new instruments to make observations that is much more precise than before or that cannot be observed before. Researchers can carry out experiments to collect data about the size and the nature of the research problem (and not the solution).

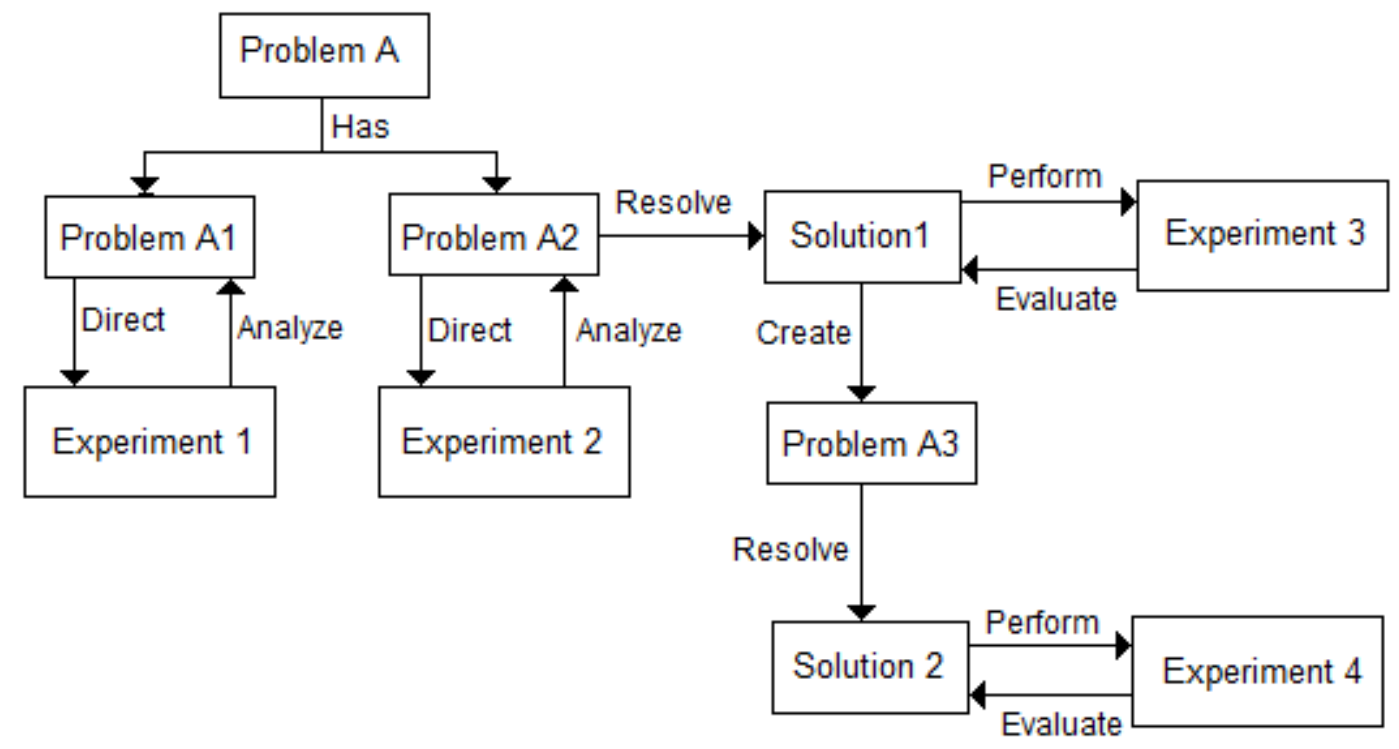

Figure 7: An instance diagram of an example research process. Note that the physical situation instances are not drawn here for presentation clarity. 
Figure 7 shows an instance diagram of an illustrative, example research process, and details about the physical situation instances are not drawn for clarity. In this example, the original research problem is divided into two specific problems (i.e., A1 and A2). Preliminary experiments (i.e., 1 and 2) are carried out. It is found that problem A1 is not significant, so a simplifying assumption is made to ignore problem A1. Problem A2 is significant, and solution 1 tries to solve this problem. Experiment 3 evaluates whether solution 1 produces good results. By analyzing the results, it is found that solution 1 has problem A3. Therefore, solution 2 is designed to solve problem A3. Experiment 4 evaluates solution 2 and concludes whether a good solution is found.

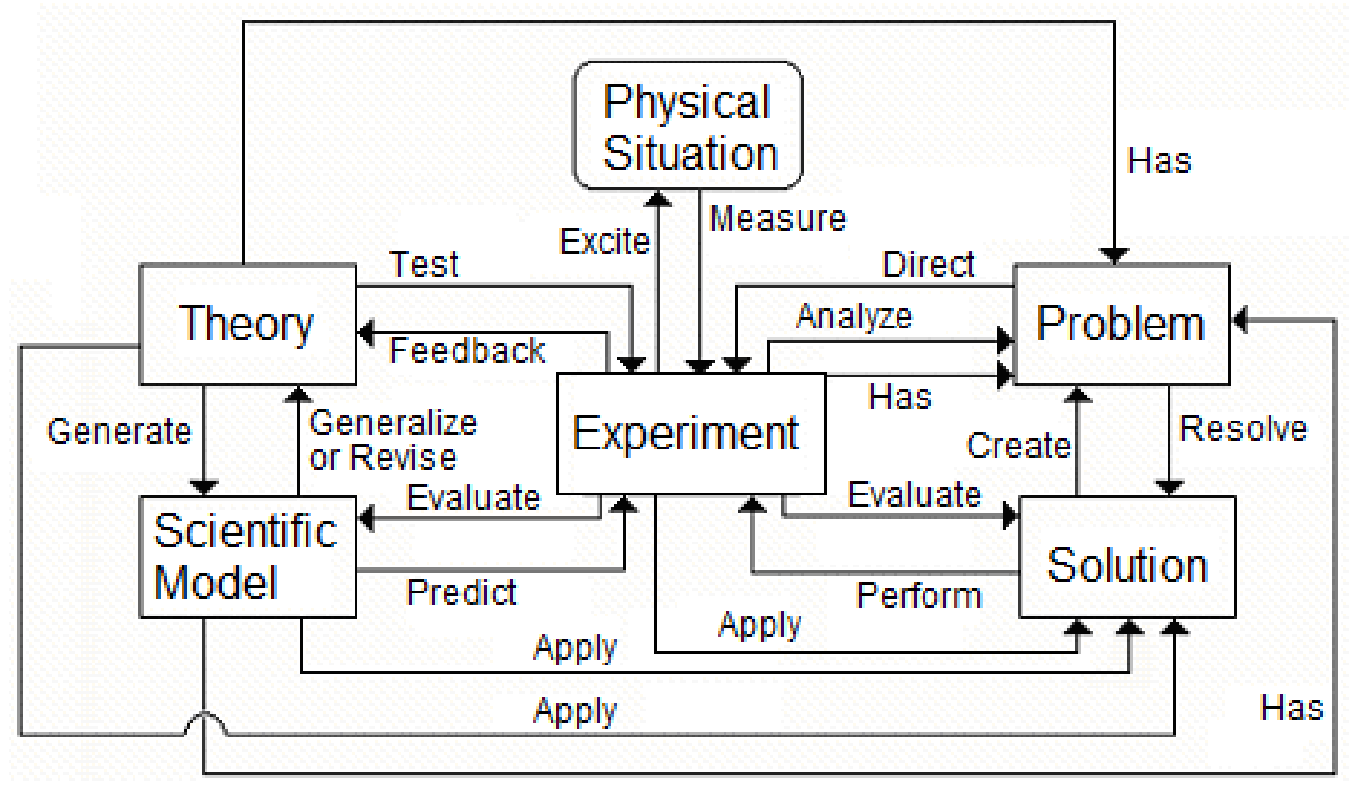

Figure 8: A unified process model of scientific research that combines the notion of scientific studies, applied science and research.

Figure 8 shows a unified process model that combines the process model for scientific study and the one for research. The unified process model added three processes that apply either the theory entity or the scientific model entity to the solution entity. These two processes are added in order to account for applied science (Boon, 2006; Morrison, 2006) that applies known scientific models and theories to solve practical, technical research problems. As Boon (2006) examined the case of fluid flows, known scientific models and theories in hydrodynamics may not be adequate to predict accurately quantities in the field or practical situations (rather than controlled 
experiments in scientific studies) that the technical problem originates. Such model and theories need to integrate technical knowledge in hydraulics to develop more realistic models for solving technical problems in practical situations.

In Figure 8, three processes, with the label "has", are added in the unified process model in order to relate the theory and scientific model entities with the problem entity. These three processes describe the case when the theory, scientific model and experiment entities have unresolved problems. For example, classical theory could not explain the black-body radiation spectrum. Such unexplained observation may become research problems. Scientists may develop a completely new theory (i.e., the quantum theory of Max Planck) or extend existing theory to explain the phenomena. These two processes with the label "has" suggest the cause of the confusion that scientific studies and research are synonymous. This is because the theory and scientific model sometimes can be embedded as some parts of research. However, there are many types of research that do not need a scientific model or a theory, for example, philosophical investigations.

Figure 8 distinguishes between basic scientific research (or pure scientific research as in Hansson, 2007) and applied scientific research. For basic scientific research, the targeted research problem is related to the theories, scientific models or experiments. This corresponds to three directed lines that are labeled "has" from the theory, the scientific model or the experiment entity to the problem entity. Basic scientific research may also resolve problems in experiments. For example, the research may be involved in the use of more sophisticated instruments to obtain better precision in experimental results. For applied research, the targeted research problem is not concerned with problems with the established theory or scientific model. Instead, applied scientific research uses the knowledge related to theories, scientific models or experiments to solve the targeted research problems. This corresponds to three directed lines that are labeled "apply" from the theory, the scientific model or the experiment entity to the solution entity. The difference between basic and applied scientific research is whether the scientific knowledge is a problem or is applied to formulate the solution. For some scientific research problems, they have both basic and applied scientific research elements, so these two types of scientific research overlap each other. 
Scientific research is a kind of research, so we argue that:

Definition 4: A scientific research problem is a research problem that is related to any elements of scientific studies (Figure 1,5).

By definition, a scientific research problem is about basic scientific research because the problem is related to the elements of scientific studies. A scientific research problem is more general than a hypothesis of the scientific method advocated by the Vienna Circle. For example, scientific instruments are designed and built for the purpose of making observations of rare phenomena. Building such scientific instruments may itself be a research problem because this may pose great technical challenges. The data collected from such instruments provide the first evidence of some unknown phenomena. There may be any theory at the time to justify the research problem as a hypothesis. However, since the research problem is related to gathering information to enable scientific studies, such activities should be classified as scientific research. Moreover, such scientific instruments contain technical knowledge that other scientists need to acquire and then replicate the results, as well as using such instruments to study other phenomena. Thus, such research on building scientific, precision instruments is also part of the scientific studies.

\section{Scientific progress}

Philosophy of science treated scientific studies as research. As a result, scientific progress and change are also seen in the light of progress or changes in research rather than scientific studies. The idea of paradigm shift (Kuhn, 1962) can be applied not just to science subjects but also research in other non-science subjects (Bod et al., 2006). For instance, philosophy of science was once dominated by the common notion of scientific method. Later, the paradigm shifts toward the use of falsification to determine the surviving theory (Popper, 1959) as the scientific method. Some (e.g., Hansson, 2006) seeks evidence from scientific literature to determine if falsification is commonly used in science. Recently, science is thought to progress in a revolutionary manner by shifting paradigms (Kuhn, 1962). These studies are research works in 
philosophy and not science, and yet they can be understood by Kuhn's idea of paradigm shifts. As in many research works, these studies are kept focused by the research issues. On the other hand, scientific research (Figure 8) makes progress by focusing on research issues related to producing better experiments, models or theories. Experiments are better (Franklin, 1981) than older ones, for instance, if better instruments will provide more precise information with less noise in the data. Models are better than previous ones if they will make more accurate, reliable predictions (Franklin et al., 1989) for a wide variety of experiments. Theories are better than established ones if they will subsume or explain more models or observations. Therefore, we argue that philosophy of science should have a better balanced focus between the mechanism of and the content of scientific progress.

Applying our process model to understand scientific progress, Figure 9 shows an illustrative example of multiple instances of the theory entity, the scientific model entity and the experiment entity. This example has three theories: A, B and C. Scientific model 1 is based on theory A and it models the physical situation 1 that experiment $\mathrm{I}$ is engaged in. Likewise, scientific model 2 is based on theory B and it models the physical situation 2 that experiment II is engaged in. Theory $\mathrm{C}$ appeared in this case to be more general than theory A and theory B because two scientific models (i.e., 3 and 4) are based on this theory; these two models describe two different physical situations that experiment I and II are engaged in.

Figure 9 illustrates an example of how complex it is when comparing competing theories to account for different phenomena observed in experiments. Figure 9 depicts the theories as being distinct from each other. In practice, theories can overlap with each other because they are describing the same subject of investigation. For instance, theory A may share one principle with theory B but other principles are not shared. Likewise, the scientific models in Figure 9 are shown as distinct but competing models may be very similar with a large knowledge overlap and a small difference (e.g., some assumptions) between them. Such an instance diagram like Figure 9 helps us to appreciate better the possible complexities of research programmes (Lakatos, 1977), scientific change (Kuhn, 1962) or scientific progress (Lauden, 1987). 


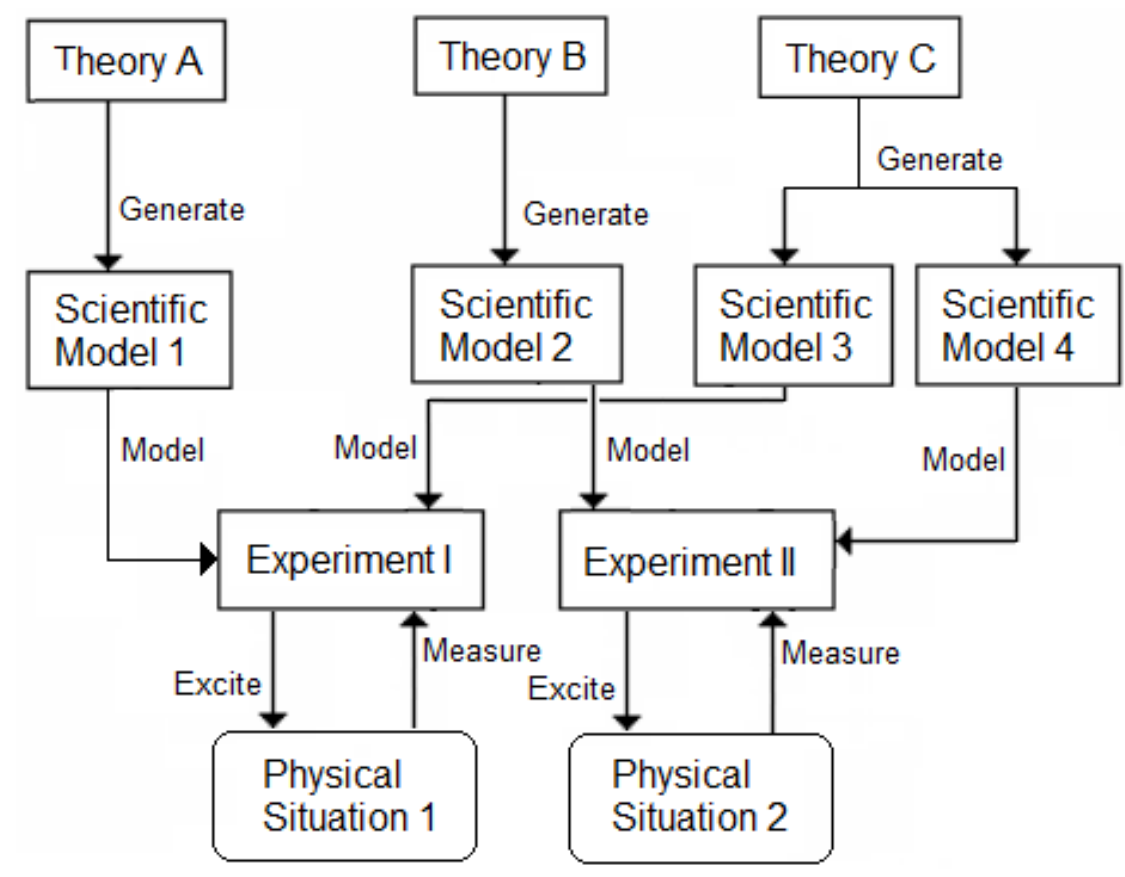

Figure 9: An instance diagram of an example of multiple instances of the theory, scientific model and experiment entities.

Models and experiments can be readily compared since they directly refer to similar abstract or physical situations. However, philosophers (e.g., Kuhn, 1962) have doubted whether theories can be compared because these theories are different understanding of or different sets of belief of nature. Difficulties to compare theories arise from the different terminologies of different theories, where different terminologies are thought to be describing different things or aspects that cannot be compared. While it is not straightforward to compare two different theories when they have different terminologies, we believe that this does not mean it is impossible to compare theories. Obviously, in order to compare two different theories, there must be some commonality between them. Based on the commonalities of different theories, scientists can come up with new methods of measurements or new quantities for comparison. In addition, since scientific theories and scientific models are usually formalized into some logical or mathematical descriptions, it may be possible to deduce consequences from these commonalities for comparisons. In some cases, one theory is found to be subsumed by another more general theory. For example, Newtonian mechanics is shown to be an approximation of the theory of general relativity. 
A theory may not be supported by every experiment against another theory in terms of prediction accuracy, explanative power, simplicity, etc. If one theory is supported by every experiment but the other theories are not, then scientists would switch their allegiance (although this is not a logical necessity until proven because future experiments may indicate otherwise). On the other hand, a stalemate situation may occur where one theory is good at some experiments but not as good as another theory in other experiments. In this situation, scientists may ponder whether there is a line differentiating the applicability of different theories or wait until further evidence or experiments or better theories to come. For example, Newton's theory of motion is not abandoned completely. Newton's theory of motion is still the preferred one in solving mechanical engineering problems in our daily life. While scientific change or progress can be a very complex process as Feyerabend (1975) has pointed out, this does not necessarily mean that there are no underlying forces that drive the scientific change or progress. Scientists are faced with a complex decision to favor the use of a particular theory, or model or experiment.

By using the guiding principles in the choice of theories, such as the principle of parsimony, it is possible to link the process model with some theory of science (Beth, 1951) or with the choice of theory. The guiding principles that choose a theory can be used by individual scientists in favoring a particular theory. However, the prerequisite to such a choice also depends on the set of experiments that the theory excels compared with other competing theories. Scientists have the further option of not forming any allegiance to any specific theory on the basis of appealing to these guiding principles. Instead, scientists can design and carry out experiments in order to select the surviving theory in question. Instead of viewing these guiding principles as selecting a theory, they can be used as objectives in designing experiments to put theories into acid tests (i.e., experiments). For example, in string theory, an interpretation of the recent quest to unify all the known fundamental forces (i.e., electromagnetic force, gravitational force, weak nuclear force and strong nuclear force) is driven by the desire to satisfy the principle of parsimony. This principle is particularly noteworthy because it is related to the aim of developing theories, which generalizes the scientific models into a set of general/universal statements (Table 1) that are applicable within the regime of study. 


\section{Scientific Study Development}

We can also apply our process models to define and understand the different stages of the development of a scientific study. Keeping in mind the development of physics as an archetype of mature science, we propose that:

Definition 5: A mature scientific study is a scientific study that contains at least one empirically established general scientific theory and more than one empirically established scientific model.

This definition is consistent with definition 1 , and it implies that a mature scientific study has some experiments which support the empirically established theories and/or models. Thus, a mature scientific study must have all the elements of a scientific study, and these interlocking elements should provide a coherent, comprehensive account of the subject of studies. A mature scientific study should have established models to describe at least some of the physical situations accurately, in order to demonstrate its predictive power or utility. These models should be subsumed by some established general theory. This is because there are so many models to account for so many different situations that a general theory is needed to identify the underlying concepts and their relationships. Without a general theory and possibly associated focused theories, these models appear as disconnected pieces of knowledge of the subject.

A scientific model is established when it can make accurate predictions that other models cannot. Also, the established models should be domain-specific rather than random models used for hypothesis testing. This is because scientific models should make use of domain-specific knowledge to demonstrate their close connections to the subject of study, but such random models have little domain-specific knowledge that shows understanding of the subject.

A scientific theory is said to be established when:

(a) many different types of experiments support it;

(b) it has constructed many models that made accurate predictions; and

(c) it has wide spread acceptance amongst scientists. 
Sometimes, (a) and (b) are combined together. For our example in Figure 4, results of the four types of experiments support Newtonian mechanics by showing that the models in Figure 3 can accurately predict the measurable quantities in equation (1) (4). A recent example is the theory of general relativity, which is supported by various famous experiments (e.g., Eddington experiment, Gravity Probe B experiment, Pound-Rebka experiment and Hafele-Keating experiment) that are carried out after the publication of the theory of general relativity.

We propose that another type of scientific study is:

Definition 6: A developing scientific study is not a mature scientific study (as in Definition 5) and contains either at least an empirically established scientific model or an empirically established scientific theory.

This definition also implies that a developing scientific study has some experiments which support the empirically established scientific theory or scientific model, but not both (in order to distinguish this type of scientific study from a mature one). For instance, I consider that the study of emerging web science (Berners-Lee et al., 2008) as a developing scientific study because (a) it has a well-known random surfer model of web page visits and (b) it has well-known empirical relationships (e.g., the frequency distribution of web page sizes follows Zipf law). I do not consider web science as a mature scientific study because it does not have a general scientific theory that covers wide ranging aspects of web science (e.g., web architecture, web growth and web page visits).

Finally, we propose that:

Definition 7: A formative scientific study is not a developing scientific study (as in Definition 6) but it is an empirical study with some established empirical research methodology.

This definition specifies that a formative scientific study (e.g., (Oelkers, 1998)) has knowledge about experiments and the related physical situations in which these 
experiments are carried out. The empirical research methodology on how to conduct the experiments should be widely accepted for reproducible results, or those that can be relied on. Such studies may have models and theories but they lack an established scientific model to provide accurate predictions, or they lack an established scientific theory that has wide-spread significance in the subject. Such formative scientific studies are usually limited in scope, so they rarely form a discipline and they may appear as non-mainstream publications in other related disciplines. We avoid the use of terms, like pseudoscience or proto-science, because of their loaded connotation.

It should be noted that academic papers need not include all the elements of scientific studies, because the papers typically focus on a certain aspect of their scientific subject. A theoretical paper may synthesize a theory based on past works, or derive an important mathematical relationship from established laws. Einstein's paper on theory of general relativity is an example. At the other end of the spectrum, an empirical paper may focus on the evaluation of a model.

This charted course of a scientific study suggests that our process model of scientific study is applicable not just to science but also to other subjects. For example, law is a subject that has its legal theory, its principles of law, and its precedence of events, in which points of law are found. Also, law enforcement agencies carry out criminal investigations similar to scientific investigations. Unlike scientific studies, law does not have models that quantify the physical situations. In law, quantification is used to provide measures of the reliability of the supplied evidence for judgment. Therefore, we argue that a scientific study is not only defined by its way of scientific investigation, but also by how scientific knowledge is organized into interacting elements, i.e., theories, models, experiments and physical situations, and by its role.

There are studies that are mainly concerned with theories and models. For example, optimization theory in mathematics aims to find optimal solutions to problems that arise from situations. Typically, the problem-solution pair is applicable to a class of situations. The objective function and the related constraints define the problem, which is the underlying reason for (or the theory behind the need of) the solutions that we are developing. The solution is a normative model, where the optimization theory prescribes an optimal, or near optimal or an efficient solution. These models do not 
have to describe the physical situation accurately. In fact, they can distort and drive the physical situation so that good performance can be obtained.

Computer science is an interesting discipline because it covers a wide-range of topics. When it is concerned about the construction of computers, it is an engineering subject. When it is concerned with the use of computers for scientific purposes (e.g., building and testing computational scientific models for weather forecasting), it becomes a science subject. Likewise, multidisciplinary subjects draw on theories, methods, models, etc. from a number of disciplines. For example, cognitive science is such a subject that draws expertise in psychology, linguistics, artificial intelligence, neuroscience, etc. At present, cognitive science may be considered as a developing scientific subject since it has some successful scientific models or theories, but it does not have any general scientific theory that covers across disciplines for it to be considered as a mature scientific study.

\section{Related work}

Philosophy of science focuses on many different aspects of science, ranging from issues about truth, objectivity (Popper, 1972, Kuhn, 1977) and observation, to falsification (Popper, 1959), research programmes (Lakatos, 1977), scientific revolution (Kuhn, 1962), scientific progress (Lauden, 1987), the transitivity of choice of theory (Baumann, 2004) and theory change (Mattingly, 2005). Given this vast literature in philosophy of science, we have to be highly selective in reviewing only directly related and possibly complementary works. First, our process model cannot be a computational philosophy of science (Thagard, 1993) since our main interests are in describing scientific studies and not simulating them using artificial intelligence techniques to gain insights.

Second, our process model of scientific study is different from the common notion of scientific methods, which is originated from the Vienna Circle. This common notion (Weston, 1987) of scientific methods undergoes a number of (sequential) stages as follows. First, scientists make some observations or some description of a phenomenon. Second, they formulate a hypothesis to explain the observation or 
phenomenon. Third, they make predictions using the hypothesis. Fourth, they perform experiments to verify or refute the hypothesis. By contrast, our process model of scientific study is less restrictive than the notion of scientific method described previously. We argue that scientific research does not pre-occupy itself only on the hypothesis formation and testing. Instead, scientific research starts with scientific research questions (Definition 4) instead of hypotheses; and such questions may be more general than a hypothesis. For instances, our process model describes scientists building precision instruments for unobserved phenomena, or the research question is about a one-off historical event (e.g., meteorite-impact hypothesis for the extinction of dinosaurs). In applied science, scientists apply their scientific knowledge to solve technical problems that do not need to be related to any scientific theory or phenomena.

Third, our process model is different from philosophical analysis, because each process model may develop into data models or transform into their instance models (or instance diagrams, e.g., Figure 2 and 4) which are absent from philosophical analysis. Specific constraints are imposed on the relationships between entities in the process model, although these constraints are not added for clarity of presentation in this paper. By contrast, philosophical analysis does not have such constraints. When process models are transformed into detailed data models, such models may have normal forms to comply with, whereas philosophical analysis does not deal with such details. In summary, the process model can be developed into a detailed, formal description of the entities and their relationships, whereas philosophical analysis provides a general description without a formal procedure for detailed model construction.

Fourth, our process model is similar to but different from the abstract picture (Figure 1 of (Giere, 2004)) of a view of scientific theories. In our process model, theories and experiments are explicitly modeled as entities. Our process model also considers scientific models as descriptions of the situation that is being studied. In fact, an experiment is a physical situation in which measurements are made. A model is an abstract (or conceptual) situation approximating the physical situation that is being studied. This abstract situation may represent a particular type of physical situation or a family of types of physical situations. A theory is a discourse of certain scientific 
subject in our process model. This discourse highlights certain general statements, like assumptions and principles, which are used in constructing and generalizing scientific models.

Gauch (2003) proposed a PEL model on reasoning for scientific inquiry. He has freed scientists from many philosophical impasses but PEL is focused on reasoning. This is because Gauch wants to claim that scientific studies produce objective, rational knowledge about reality. As a result, PEL has neglected experiments, models and theories that are priced dearly by scientists. Another concern about PEL is that it can be equally applied to legal reasoning for legal judgment in court and drawing conclusions in scientific studies. This raises a question as to whether PEL is a general valid reasoning process for making conclusions beyond science or a distinguishable feature of science. If PEL is about valid reasoning for daily life, then such valid reasoning ability should be treated as a skill not just for scientists but for any educated person.

Gauch (2003) also made "four bold claims", which are about the basic qualities of science. These qualities are rationality, truth, objectivity and realism. They belong to different elements or processes of our process model of scientific study. First, some theoretical statements, like laws or principles, are intended to be true in the sense that they are thought to exist in all or at some of their operating regime. Second, scientific models are realistic if they can predict quantities accurately and reliably for a variety of situations. Third, established scientific knowledge is consistent, so it is considered rational. Finally, the knowledge created via scientific study is objective in the sense that it is accessible to other scientists for validation or challenge.

Apart from the aim of developing a model of scientific study, our process model is related to the engineering tasks of automating the management of scientific and research activities (such as paper review, research proposal vetting, etc). Our process model can be thought of as a more comprehensive, higher level model of the scientific knowledge infrastructure articulated by Hars (2001). Such an infrastructure provides details of scientific research based on studies in philosophy of science. Our process model adds the additional dimensions about scientific models and solutions to research problems to such a scientific knowledge structure. Our qualitative process 
model complements current e-science activities (e.g., De Roure et al., 2003) that focus on the more quantitative aspect of scientific study. That is solving large-scale dataintensive number crunching problems by grid computing. In addition, our process model forms a basis to develop data models (Silberschatz et al., 2005) that capture and organize knowledge for science and research. For example, some research work organized knowledge bases into some kind of ontology to assist scientific knowledge management (e.g., Kingston, 2002), and some focuses on the data integration and detailed scientific workflows (e.g., Ludäscher et al. (2006)) that are unconnected to issues in the philosophy of science. Some even include search facility (e.g., Shadbolt et al., 2004). This complements existing library studies that, for instance, investigate how best to create taxonomy of knowledge (e.g., Saracevic and Kantor, 1997).

Our process model for research is at a higher level of abstraction than the more detailed computational model of human problem-solving (e.g., Simon, 1977; Bhaskar and Simon, 1977), and models of human problem-solving (e.g., Broadbent, 1977; Dörner, 1975). It is possible to integrate detailed models of problem solving with our process model of research. However, this is outside the scope of this paper because the purpose of developing our process model of research is to differentiate and integrate research and science. This is done by identifying the major elements of research and integrating them with our process model of scientific study.

In the past, some philosophers (e.g., Liu, 1997; 1998) have discussed models, theories and their relationship, but it is rare to find a more comprehensive framework, as in this paper, that encompasses science, research and scientific progress. There are also works (Bod, 2006) that apply tools or techniques in computer science in philosophy of science. However, these works do not use process modeling nor data modeling methodologies (e.g., Silberschatz et al., 2005), and these works focus on addressing certain specific aspects of science.

Our process model is very similar to the theory of idealization (Liu, 2004), even though our model is developed independently from it. While the theory of idealization regards models and theories as idealizations (Nowak, 1972; McMullin, 1985), we regard: 
(a) laws in theories are expressing the underlying true relationship as found in physical situations; and

(b) scientific models are approximating the physical situations (Niiniluoto, 1987; Marquis, 1991).

This is because theories and scientific models play different roles in the organization of scientific knowledge. Scientists want to discover the underlying relationship or law that is at play in their subject of study. What is believed to be imperfect is the controllability of the experiment that is responsible to bring the laws onto the surface from the messy data. Otherwise, if the inaccuracies of the law are not due to the controllability of the experiment, then some scientists will consider that it is worthwhile to investigate what is not accounted for by the concerned law. Some scientists may want to further the limit of predictability by inventing better controlled experiments in order to observe whether the existing law holds. If it does not hold, this is an important anomaly. If it holds, it provides a benchmark figure about the limit of predictability of the law for its application. Such confirmation study is carried out to test the famous equation, $E=m c^{2}$ (Rainville et al., 2005). On the other hand, scientific models try to describe the physical situation as accurately as possible. When scientists found that there are inadequacies in their scientific models, they may try to improve them by incorporating more domain-specific technical knowledge to make their scientific models more realistic (Boon, 2006), or they may develop a new theory with a new set of related scientific models as an alternative to the existing ones.

In our process models, scientific models are not "true" nor "approximately true" (Weston, 1987) in the sense that models are only accurate or inaccurate. They are the approximations (or idealizations) of physical situations. However, established statements in theories are not intended to be approximation nor idealization. Instead, they are thought to be true enabling logical deduction from these statements (Aliseda, 2004). Because they are thought to be true according to the theory, scientists design controlled experiment to measure the precision of predictions that are derived from such statements in the theory. This differentiation of roles between theories and models set our process model apart from previous works (Niinluoto 1987; Weston, 1987; Liu, 1999; 2004) that consider both theories and models to be approximately true. 


\section{Conclusion}

Based on conclusion 1 and the process models developed in this paper, we answer our earlier questions in Section 1:

(a) science is not solely concerned with scientific research;

(b) scientific research has a scientific research question to answer (Definition 4), and a hypothesis is a restricted form of scientific research question. Since scientific studies are more general than scientific research, they have study aims that are more general than answering hypotheses;

(c) While the scientific method advocated by the Vienna Circle is useful to many scientists, it is not the only method to carry out scientific studies, because some scientific studies are not concerned with a hypothesis;

(d) Paradigm shift by Kuhn is applicable not only to science but to other subjects. When it focuses on changes in the established or formative scientific knowledge, it is related to science. The scientific method of the Vienna circle is too general because the method is applicable to criminal investigations, where a hypothesis is a theory of how the crime is carried out, and the phenomena are the evidence found. Similarly, the PEL model by Gauch is applicable to law or philosophy in which knowledge is codified into logical statements for deductions and for testing valid reasoning. Therefore, we argue that future investigation about science should place an equal emphasis on its processes and its knowledge;

(e) Our process model of scientific studies differentiates the roles of theories and scientific models. While statements in theories are intended to be true, scientific models are intended to be accurate. The different roles of theories and scientific models set our process model apart from other philosophical work on the concept that scientific knowledge is "approximately true" (Weston, 1987);

(f) Some theories are incommensurable because they are about different subject of studies. Some theories about the same subject may not be immediately commensurable, because they use different terminologies. However, we argue that if these theories are applicable to the same physical situation, scientists will develop measures to quantify their 
differences, similarities, generalities or their relationship with each other (even though this process may take some time);

(g) Not all computational models are complex versions of scientific models, because they may be too difficult to be understood, or they do not relate to any scientific models;

(h) Using our process model of scientific study, we have identified different stages of scientific study development (in Section 6). Obviously, these are not the only stages, because finer stages can be identified.

Since we argue that future studies about science need to put a more balanced emphasis between its processes and its elements, we define science in concrete terms using our process model by first stating two related concepts called scientific understanding and scientific knowledge as follows:

Definition 8: Scientific understanding of a subject is the ability to analyze or to apply the underlying concepts or their relationships that are found across different types of physical situations, in order to construct models which can accurately and reliably predict quantities that are measurable from (novel) physical situations.

Implicitly, this definition assumes that understanding involves knowing the presuppositions, assumptions and conditions of applying the concepts and relationships (e.g., (Kosso, 2007)). Such presupposition, assumptions, etc. may be explicitly stated in the theory. The level of prediction accuracy in the previous definition depends on the currently achieved prediction accuracy, so this level advances as the scientific study advances. Together with our process model of scientific study, the previous definition helps us to define:

Definition 9: Scientific knowledge is aimed at the scientific understanding (as in Definition 8) of a particular subject, and is related to or belongs to some elements of scientific studies (Figure $1,5)$. 
This definition implies that scientific knowledge is related to theories, models, experiments or the related physical situations of study. Using these two concepts, science (Chalmers, 1999) is defined as follows:

Definition 10: Science is a body of scientific knowledge (as in Definition 9) which is established by scientific research (Figure 8), and which is applied to solve technical problems.

This definition involves both the scientific knowledge and scientific research to define science. As alluded earlier, scientific research differs from the scientific method in two respects: (1) scientific knowledge is related not just to theories but also models and experiments, and (2) scientific research problems are more general than hypotheses because these problems can be about scientific models or experiments, but these problems are more focused on the scientific knowledge than hypotheses that are applicable to other subjects (e.g., criminal investigation). This definition of science includes both the basic science and applied science. In this definition, technical problems are not trivial to solve, and they are not directly related to problems of the established scientific knowledge (see Figure 8). We argue that these definitions together with our process models form a basis for discussing philosophical issues about science in a context that is better balanced between scientific knowledge and scientific processes, where this basis is sufficiently distinct from studies of other disciplines.

\section{Acknowledgment}

I thank Dr. Edward Dang for commenting on an earlier draft of this paper. He got a B.A. in Physics from the University of Oxford, a Ph.D. in Physics from the University of Bristol and has published papers in reputable, international Physics journals. I also thank the reviewers for the critical comments to improve the paper. The final publication is available at Springer via http://dx.doi.org/10.1007/s10699-009-9168-9. 


\section{References}

Achinstein, P. (1965) Theoretical models, The British Journal of Philosophy of Science 16(62): 102-120.

Alexander, P. (1958) Theory-construction and theory-testing, The British Journal of Philosophy of Science 9(33): 29-38.

Aliseda, A. (2004) Logics in scientific discovery, Foundations of Science 9(3): 339363.

Bailer-Jones, D.M. (1999) Creative strategies employed in modeling: a case study, Foundations of Science 4(4): 375-388.

Bailer-Jones, D. (2003) When scientific models represent, International Studies in the Philosophy of Science 17(1): 59-74.

Bartholomew, D.J., and Knott, M. (1999) Latent Variable Models and Factor Analysis, Arnold, London.

Baumann, P. (2004) Theory choice and the intransitivity of 'is a better theory than', Philosophy of Science 72(1): 231-240.

Berners-Lee, T., Hall, W., Hendler, J., Shadbolt, N. and Weitzner, D.J. (2006) Creating a science of the web, Science, 313(5788): 769-771.

Beth, E.W. (1951) Fundamental features of contemporary theory of science, The British Journal of Philosophy of Science 1(4): 291-302.

Beveridge, W.I.B. (1957) The Art of Scientific Study, Norton \& Company, New York.

Białkowski, G. (1998) Is physics an universal science? Foundations of Science 1(1): $9-21$.

Bhaskar, R. and Simon, H.A. (1977) Problem solving in semantically rich domains: an example from engineering thermodynamics, Cognitive Science 1(2): 193-215.

Bod, R. (2006) Towards a general model of applying science, International Studies in the Philosophy of Science 20(1): 5-25.

Bod, R., Boon, M. and Boumans, M. (2006) Introduction to the symposium 'applying science', International Studies in the Philosophy of Science 20(1): 1-3.

Boon, M. (2003) Technological instruments in scientific experimentation, International Studies in the Philosophy of Science 18(2-3): 221-230.

Boon, M. (2006) How science is applied in technology, International Studies in the Philosophy of Science 20(1): 27-47. 
Broadbent, D.E. (1977) Levels, hierarchies, and the locus of control, Quarterly Journal of Experimental Psychology 29: 181-201.

Brodaric, B. and Gahegan, M. (2006) Representing geoscientific knowledge in cyberinfrastructure: challenges, approaches and implementations. Sinha, A.K. (Ed.) Geoinformatics: Data to Knowledge, pp. 1-20, Geological Society of America, Inc., Colorado, USA.

Chalmers, A.F. (1999) What is this Thing called Science? Open University Press, Buckingham.

Cleland, C.E. (2001) Historical science, experimental science and the scientific method, Geology 29(11): 987-990.

Damper, R.I. (2006) Thought experiments can be harmful, The Pantaneto Forum 22.

Davy, K. (2003) Is mathematical rigor necessary in physics?, The British Journal of Philosophy of Scence 53(3): 439-463.

De Roure, D., Jennings, N.R. and Shadbolt, N.R. (2003) The semantic grid: a future e-science infrastructure. F. Berman, G. Fox and T. Hey (Eds.) Grid Computing Making the Global Infrastructure a Reality, 437-470, Wiley, England.

Dörner, D. (1975) Wie Menschen eine Welt verbessern wollten [How people wanted to improve the world], Bild der Wissenschaft 12: 48-53.

Einstein, A. (1905) Zur Electrodynamik bewegter Körper [On the electrodynamics of moving bodies]. Annalen der Physik 17: 891-921.

Franklin, A.D. (1981) What makes a 'good' experiment? The British Journal of Philosophy of Science 32(4): 367-374.

Franklin, A.D., Anderson, M., Brock, D., Coleman, S., Downing, J., Gruvander, A., Lilly, J., Neal, J., Peterson, D., Price, M., Rice, R., Smith, L., Speirer, S. and Toering, D. (1989) Can a theory-laden observation test the theory, The British Journal of Philosophy of Science 40(2): 229-231.

Feyerabend, P.K. (1975) Against Method: Outline of an Anarchistic Theory of Knowledge, New Left Books, London.

Gauch, H.C. (2003) Scientific Method in Practice, Cambridge University Press, Cambridge.

Giere, R.N. (2004) How models are used to represent reality, Philosophy of Science 71(5): 742-752.

Hansson S.O. (2006) Falsificationism falsified, Foundations of Science 11(3): 275286. 
Hansson, S.O. (2007) Values in pure and applied science, Foundations of Science 12(3): 257-268.

Hars, A. (2001) Designing scientific knowledge infrastructures: the contribution of epistemology, Information Systems Frontiers 3(1): 63-71.

Hartmann, S. (1996) The world as a process: simulations in the natural and social sciences. Hegselmann R., Mueller, U. and Troitzsch, K.G. (Eds) Modeling and Simulation in the Social Sciences from the Philosophy of Science Point of View, Kluwer Academic Press, 77-100.

Hennig, C. (2010) Mathematical models and reality: a constructivist perspective, To appear in Foundations of Science.

Humphreys, P. (1995) Computational empiricism, Foundations of Science 1(1): 119130.

Kingston, J. (2002) Merging top level ontologies for scientific knowledge management, Proceedings of the AAAI Workshop on Ontologies and the Semantic Web, Edmonton, Canada.

Korshland, Jr., D.E. (2007) The cha-cha-cha theory of scientific discovery. Science 317(5839): 761-762.

Kosso, P. (2007) Scientific understanding, Foundations of Science 12(2): 173-188.

Kruse, M. (1997) Variation and the accuracy of predictions, The British Journal of Philosophy of Science 48(2): 181-193.

Kuhn, T.S. (1962) The Structure of Scientific Revolutions, University of Chicago Press, Chicago.

Kuhn, T.S. (1977) Objectivity, value judgment and theory choice, in T. S. Kuhn, The Essential Tension: Selected Studies in Scientific Tradition and Change, University of Chicago Press, Chicago, 320-339.

Lakatos, I. (1977) The Methodology of Scientific Research Programmes, edited by J. Worrall and G. Currie, Cambridge University Press.

Laudan, L. (1987) Progress or rationality? the prospects for normative naturalism, American Philosophical Quarterly 24: 19-31.

Liu, C. (1997) Models and theories I: the semantic view revisited, International Studies in the Philosophy of Science 11(2): 147-164.

Liu, C. (1998) Models and theories II: issues and applications, International Studies in the Philosophy of Science 12(2): 111-128. 
Liu, C. (1999) Approximation, idealization, and laws of nature, Synthese 118(2): 229256.

Liu, C. (2004) Laws and models in a theory of idealization, Syntheses 138(3): 363385.

Ludäscher, M., Lin, K., Bowers, S., Jaeger-Frank, E., Brodaric, B. and Baru, C. (2006) Managing scientific data: from data integration to scientific workflows. Sinha, A.K. (Ed.) Geoinformatics: Data to Knowledge, pp. 109-130, Geological Society of America, Inc., Colorado, USA.

Magnani, L. (1999) Withdrawing unfalsifiable hypothesis, Foundations of Science 4(2): 257-268.

Marquis, J.-P. (1991) Approximations and truth space, Journal of Philosophical Logic 20(4): 375-401.

Mattingly, J. (2005) The structure of scientific theory change: models versus privileged formulations, Philosophy of Science 72(2): 365-389.

McMullin, E. (1985) Galilean idealization, Studies in the History and Philosophy of Science 16, 247-273.

Miscevic, N. (2001) Science, commonsense and philosophy: a defense of continuity (a critique of "network apriorism"), International Studies in the Philosophy of Science 15(1): 19-31.

Moor, J.H. (1978) Three myths of computer science, The British Journal for the Philosophy of Science 29(3): 213-222.

Morrison, M. (2006) Applying science and applied science: what's the difference? International Studies in the Philosophy of Science 20(1):81-91.

Morton, A. (1993) Mathematical models: questions of trusthworthiness, The British Journal of Philosophy of Science 44(4): 659-674.

Nagel, T. (1974) What is it like to be a bat? Philosophical Review 83(4): 435-450.

Niiniluoto, I. (1987) Truthlikeness, Reidel, Dordrecht.

Nowak, L. (1972) Laws of science, theories, measurement, Philosophy of Science 39(4): 533-548.

Nugavey, R. (1985) A study of theory unification, The British Journal for the Philosophy of Science 36(2): 159-173.

Oelkers, J. (1998) Empirical research in progressive education, International Journal of Educational Research, 27(8): 715-722. 
Pierce, C.S. (1878) Deduction, induction and abduction, Popular Science Monthly 13:470-782.

Popper, K.R. (1972) Objective Knowledge, Oxford University Press, Oxford.

Popper, K.R. (1959) The Logic of Scientific Discovery, Hutchinson, London.

Portides, D.P. (2005) A theory of scientific model construction: the conceptual process of abstraction and concretization, Foundations of Science 10(1): 67-88.

Psillos, S. (2000) Agnostic empiricism versus scientific realism: belief in truth matters, International Studies in the Philosophy of Science 14(1): 57-75.

Rainville, S., Thompson, J.K., Myers, E.G., Brown, J.M., Dewey, M.S., Kessler Jr. E.G., Deslattes, R.D., Börner, H.G., Jentschel, M., Mutti, P., Pritchard, D.E. (2005) A direct test of $\mathrm{E}=\mathrm{mc}^{2}$, Nature 438(22): 1096-1097.

Saracevic, T. and Kantor, P.B. (1997) Studying the value of library and information services. Part II. Methodology and taxonomy, Journal of the American Society for Information Science and Technology 48(6): 543-563.

Shadbolt, N.R., Gibbins, N., Glaser, H., Harris, S. and schraefel, m.c. (2004) Walking through CS AKTive space: a demonstration of an integrated semantic web application, Journal of Web Semantics 1(4): 415-420.

Silberschatz, A., Korth, H.F. and Sudarshan, S. (2005) Database System Concepts, $5^{\text {th }}$ edition, McGraw Hill, New York.

Simon, H. (1977) Models of Discovery : and other topics in the methods of science, D. Reidel Pub. Co., Dordrecht, Holland; Boston.

Sintonen, M. (2004) Reasoning to hypotheses: where do questions come from? Foundations of Science 9(3): 249-266.

Struan, J. (2001) Limits of problem solving in science, International Studies in the Philosophy of Science 15(3): 231-242.

Suárez, M. (2003) Scientific representation: against similarity and isomorphism, International Studies in the Philosophy of Science 17(3): 225-244.

Suppes, P. (1960) A comparison of meaning and use of models in mathematics and empirical sciences, Synthese 12(2-3): 287-301.

Suppes, P. (1995) Principles that transcend experience: Kant's antinomies revisited (Transzendentale prinzipien: eine neubetrachtung der Kantschen antinomien), Metaphysik 11: 43-54.

Suppes, P. (2007) Statistical concepts in philosophy of science, Synthese 154(3): 485496. 
Swanson, J.W. (1967) On models, The British Journal of Philosophy of Science 17(4): 297-311.

Thagard, P. (1993) Computational Philosophy of Science. MIT Press, Reading: Massachusetts.

Wiezenbaum, J. (1966) ELIZA - A computer program for the study of natural language communication between man and machine, Communications of the ACM 9(1): 36-45.

Weston, T. (1987) Approximate truth, Journal of Philosophical Logic 16(2): 203-227.

Weinburg, G.M. (2001) An Introduction to General Systems Thinking. Dorset House, New York.

von Bertalanffy, L. (1950) An outline of general system theory, The British Journal for the Philosophy of Science 1(2): 134-165. 